\title{
Film Art Crisis in the Era of Intelligent Media
}

\author{
Haihao Zheng \\ College of Arts \\ Communication University of China \\ Beijing, China \\ School of Digital Arts \\ Xi'an University of Posts \& Telecommunications \\ Xi'an, China
}

\author{
Tao Liu \\ School of Digital Arts \\ Xi'an University of Posts \& Telecommunications \\ Xi'an, China \\ College of Arts \\ Communication University of China \\ Beijing, China
}

\begin{abstract}
Going with the rapid media integration, digital media gradually turn to intelligent media, the brand new medium ecology created by media technologies have brought opportunities and challenges to all kinds of art forms inside it, especially for film the seventh art, who producers and researches have to deeply recognize the nature of intelligent media. First, this article introduces art practices that are done in all links from production to transmission and to acceptance of film art in the pro-intelligent media time, through summarizing characteristics of the era of intelligent media, it further analyzes the development crisis for film art in the era of intelligent media and raises corresponding suggestions, aiming to explore theories for the film art to meet with the new situation of intelligent media environment.
\end{abstract} media

Keywords-Intelligent media; film industry; film art; digital

\section{INTRODUCTION}

With the continuous development of computer technologies and Internet, new media has turned to be intelligent from digital and automatic. Driven by technical innovation, human being has gradually entered an era of intelligent media. Actually intelligent media are not brand new in nature, it is just a high level for the development of digital media, and digitalization is still its foundation for development, owning inherent characteristics such as interaction, technology, transmission and artistic expression and having features such as interaction, integration, big data and visualization. Based on such functions, intelligent media have completely integrated traditional and digital media, namely in the era of intelligent media, it has achieved the sound integration of software, hardware, new and old media, media forms and contents. Obviously the powerful Internet has become a mirror image of real society, besides, with the development of artificial intelligence technologies, a great number of in vitro media have optional functions as "fitting in mentality" like human being. A perceptual intelligent media ecology has gradually come into being, where human being, corresponding social relations, ideology, art aesthetics, culture and economy all will

*Program fund: Funded by the $13^{\text {th }}$ Five-Year Plan Topics of Shaanxi Education Science in 2016 (Project No: SGH16H080), Shaanxi Education Department Scientific Research Plan Project (Project No: 16JK1677) in 2016 and Shaanxi Innovation Capability Support Plan Soft Science Research Project in 2017(Project No: 2017KRM051) be greatly influenced, which will change to some degree.

Before cultural development, art goes first, with the quiet arrival of the era of intelligent media, the sensitivity of art is the most obvious. Acting as the seventh art, film is an artistic form which is generated, applied and developed with new technologies. Before the intelligent media knock at the door of the new era films themselves are advancing on the way of developing — return-developing as well.

\section{FILM ART PRACTICES IN THE ERA OF PRO-INTELLIGENT MEDIA}

Technologies are scientifically uniform and standard, generally there will be specific technical standards and specification used to describe characteristics of objective things. During the development of film art, parameter setting and technical specification of all kinds of software and hardware can be found in all aspects from film art production to release and acceptance. For example, for the same film for audiences in a cinema, there are 2D version, 3D version and IMAX version whose technical indices such as size, format and resolution differ. For audients, though there are options, yet the emotion, thought and wisdom that the films contain will not vary with the complicated parameters or versions. Seen to some degree, on the one hand, film technologies have expanded the business of films, intensifying visual and auditory effect and increasing the mass production of the film industry; on the other hand, the film art is tied by technologies, which further dissolve or dissimilate the film art, it is a tragedy for films. Therefore, in the era of pro-intelligent media we have to well treat the relation between films and technologies.

On one hand, it needs to form the creative philosophy that film technologies should serve the film art. Currently Hollywood blockbusters such as The Martian, Ant-Man, the Fast and the Furious hit the market, getting the highest box office around the world. Film technologies can be seen in these films, and almost all shots have adopted toning, for example in the film Chappie, every scene where the robot Chappie reaches needs 3D technologies. The Chappie robot model needs final process techniques such as 3D modeling, skeleton and camera tracker and even advanced makeup, producers are required to master skillfully processes such as modeling, reverse mould, coloring and makeup of mask and so 
on, and the making of scene models and props also get involved in sciences and technologies of other fields.

Stimulated and induced by Hollywood films, domestic films launched a tide of virtuosity, and any film having no new technical application or demonstration feel ashamed of release. And the films have been on the way to pure entertainment, commercial and vulgar development. Today with the box office as the sole standard to weigh films, the film art will weakened constantly. However, in the opinion of this author, for films, the core value is artistry that they contain, as a medium for communications between people, the aesthetic value of films shall be awaken but not rejected, which is a base for films to survive in art. The Assassin directed by Hou Xiaoxian is one of the best films in recent years, it is not created to please audiences, and its tedious narration is challenging the tolerance of audiences, and the $4: 3$ film size is even hard to comfort eyeballs. In order to keep the film production natural, even the whole groups would rather wait for natural winds to blow curtains than adopt blowing equipment at the era of industries to complete the shot. Probably, the box office of the Assassin is dissatisfactory, yet this author holds the opinion that the artistic creation starting with aesthetic imagination is a real film art. Just like architectures remained in ancient Roma and Egypt, however the people dream of restoring and renewing them, only the dilapidated walls and ruins can become real work of art.

On the other hand, reasonably use new media technologies to expand the transmission of film art.

First, on the film production, digital media technologies have highly improved the efficiency of film production and lowered the costs concerned. On markets, there are all kinds of film shooting devices which have adopted digital media technologies, and some HD equipment shooting can be provided such as RED Scarlet, RED EPIC, which can shoot videos with $6 \mathrm{~K}$ resolution. The film production software and systems on different platforms facilitate the film production, for example, Da Vinci Resolve provides adequate options and creative spaces for the film dimming and toning.

Second, on the film transmission, its main channels are large screens in cinemas. After completion of early films, the original tapes are completed as well, then a serious of copies are made to show at designated cinemas for which special persons are arranged for control. After entering the era of digital media, films from production to showing can be digitalized completely, with high-speed network used, the films can be showed and controlled safety at the same time at different cinemas, during the course, films are transmitted at an extremely high speed.

At last, during the stage of film acceptance, digital media technologies present more possibilities for audiences, increasing the depth and expansion of audiences to understand film works. Previously audiences know at most film production teams, director, players, film summary, posters and so on. However, in the era of digital media, with technical support, audiences may access more tidbits of film shooting in real time as well as electronic reading of films, communicate with creators directly via social media and get online film comments from professionals and so on. Audiences may access film information from more aspects. In addition, this author thinks that digital media technologies make it possible for interactions between audience at cinemas, currently the most remarkable barrage films attract more audiences who, while watching can make complaints, catharsis, comments and interaction, showing what they want and how they think. Instantly the display interface as a block between films and audiences has disappeared, and audiences directly access film works, from negative acceptance to active embrace, all are supported by digital media technologies. Currently barrage films, as brand new versions of films, have become standard requirements to release films.

\section{DEVELOPMENT AND CRISIS OF FILM ART IN THE ERA OF INTELLIGENT MEDIA}

Seen from the film practices of pro-intelligent media, the film art is closely related to the media environment. On one hand, film producers have to closely keep up with the development of times, on the other hand, they have to keep the art value of films, insisting on their pursuit of higher artistic state and stressing cultivating people with culture, purifying heart by art, aesthetic judgment of film art on people as well as value cultivation. However, this author thinks that technologies are invasive, though scientism is a kind of superstition, yet facing the abrupt technologies, whether film art can cope with challenges of intelligent media ecology or can correctly deal with the relations between them both require film art practitioners and researchers own forward thinking to understand. Because, in the era of intelligent media, its unique integration, intelligence and high dimension will bring huge impact on films, spoken exactly current film styles, which is completely different from the art practice of film arts in the era of pro-intelligent media.

\section{A. The Integration of Intelligent Media Removes Borders of Film Art Fields}

Currently, integration is the most drastic trend for media development, with the trend becoming mature gradually, the integration of intelligent media will take on all-media integration, bringing more possibilities for film art. In the meantime, different media such as film, TV, broadcast, magazine and so on will have no difference in nature. Core data of all media are shared, and the only differences between them are screens at terminals, besides, formats and contents can be shifted freely. In addition, 3D holographic technologies can be used to communicate with creators at any time, the integrated media have broken through the barriers between different media, providing shortcuts for communications between film art and other forms of art. (1) For creators, they, together with other art creators, will feel easy to capture info in the film database through integrated media tools, and rearrange plots according to different creative philosophies and achieve a second creation of films quickly. (2)For audiences, they can access the scenes or characters they like in films, capture pictures after online payment, and produce doll and garment of their own via 3D printers so as to create value for the films. It can said that going with the development of intelligent media technologies, the borders between film art field, cultural field, commercial field, painting art field, opera 
field and music field and so on will become much more vague, taking on a new state of field overlapping.

\section{B. High Dimension of Intelligent Media Promotes Film Art to Be Represented Via Modularization and Stylization}

Researches show, quantum mechanics have proved the influence of thought at the level of spirit, acting as media of thought transmission, art works are an advanced and highdimension medium. Seen from the amount of information, the high-dimension world has amount of information that is indefinitely times that of low-dimension world. In the era of intelligent media, the high speed development of big data is going toward the high-dimension world, of which, thick data and chain data, acting as data sources with practical value, will disclose the prospects described by film art roundly. For art creators, they ought to fully understand the subdivided demands of audiences, deeply understanding of aesthetic needs of different users.

In the era of intelligent media, the society is computed, is the consciousness of human being estimated as well? Intelligent media show a prospect as follows: Big data are basis, Internet has everything connected, all kinds of equipment and human brains are on the same network, and media provide people with information that we have had. For human being, information of human being is captured by computers and saved online, at that time, films will become a consciousness or thought, or images of facts and imagination are symbolized or symbols are visualized to show. Though familiar with such information, human being is still confused and stubborn, and maybe, only art can make them surpass it. In the high dimension era of intelligent media, films still have profound value of art, able to make people experience different life within a limited time, put eyes on themselves in a real and beautiful world, only at that time, audiences may be directors or leading actors for films, describing a different life that another they experience. At that time, films will become dreams that people see themselves, only those which create the dreams art networks consisting of artificial intelligence, big data, VR and so on, the support of huge and confused high data is just an expression of high-dimension intelligent media.

\section{Intelligence of Intelligent Media Dissolve the Perception of Aesthetic Subjects}

The most important characteristic of intelligent media is intelligence. Seen from existing Things of Internet, VR technology, machine learning, it can be predicted that the scenes at the era of intelligent media will be: all are connected, software and hardware connected, human being are connected with the nature, between them there are not only relevant interfaces to real time data access but also abilities of perception, thinking and judgment. Of intelligent media, film art will be gradually connected with audiences who can perceive, in addition to common films that audiences can watch, according to estimation of users' comments and physiological data, intelligent media may make use of the creative engine of intelligent media to generate automatically sequels of the films they have watched, of which the character design, scene dispatch and plots all are massive visual materials that have been stored, and even pictures formed by post production. In brief, in the era of intelligent media, every audience can enjoy one to one watching experience, according to the needs of audiences, the film creators many customize the films, so that the films that everyone watches are different. In the meantime, the film recreation also become more convenient, and users have higher control over and participation in films, just like barrage films that show us plots, cinema service, audiences' interaction, all are connected through short messages of barrages, which are an embodiment of medium compatibility and intelligence. However, there is a point that cannot be ignored, highly intelligent and customized service will further occupy the perception time of aesthetic subjects, mass contents that please aesthetic subjects are shown continuously at the aesthetic subjects, which make the aesthetic subjects be occupied before self thinking, and maybe, the perception on aesthetics will take on a state of being passive to accept. After all, intelligent media can be seen anywhere in the future and human life and the nature both can be stages for intelligent media to show.

\section{CONCLUSION}

The era of intelligent media has started its steps quietly, just like other works of art, films, promoted by the era of intelligent media, will change inevitably which is necessary and general and a power to push the film art changing from quantitative change to qualitative change.

Yet even within the intelligent media, the film art shall always have its core value of art remembered and insist on its unique aesthetic characters so as to avoid be to lost in the tide of high integration of new media but not act as a simple screen to display schema information; During its connection and grafting with new media, it shall avoid to lose core genes of its own so that it will not become prop of games and not be placed at a noisy corner after meeting users' needs. Steps of the era of intelligent media are approaching, for film art, the situation where opportunities coexist with challenges will become much more highlighted than ever.

\section{REFERENCES}

[1] (USA) Negroponte, Being Digital, Haikou, Hainan Publishing House, 1996;

[2] (Canada) McLuhan, Understanding Media: the Extension f Man, Beijing, the Commercial Press, 2000;

[3] (USA) Paul Levinson, translated by He Daokuan, Digital McLuhan [M]. Social Sciences Academic Press, 2001;

[4] Hu Zhifeng, Film and TV Culture and Art in the Era of Media Integration [J]. China Television, 2015(01);

[5] Kang Chuying, Discussion on Advertisement Development of Micro Films on the Background of Media Integration [J]. Press Circles, 2012(15). 